\title{
Recognizing the Ground that Lies before us as Ground: McDowell on How to Read Philosophical Investigations
}

Marie McGinn, York

'Every sign by itself seems dead. What gives it life?-In use it is alive. Is life breathed into it there?-Or is the use its life?' (PI 432)

\section{Introduction}

John McDowell presents a reading of Wittgenstein's remarks on rulefollowing which sets out to absolve Wittgenstein from the charge that he puts forward what McDowell sees as an untenable view, namely, that, when it comes to applying a rule in a new case, what counts as correct is somehow determined by the responses that the members of the relevant speech community are inclined to make ${ }^{1}$. McDowell argues that this conception of what counts as correct in a new case is not only revisionary of our commonsense view that the pattern of application of our concepts is independent of our ratification of it, but destroys the very idea that there is any such thing as someone's meaning something by the words he utters. McDowell further points out that the revisionary aspect of what is known as the communitarian interpretation is at odds with Wittgenstein's conception of his philosophical method: that one should not try 'to advance theses in philosophy' (PI 128).

I share McDowell's dissatisfaction with the communitarian reading, and I am generally sympathetic with his concern to find a reading of Wittgenstein's remarks which avoids committing him to a communitarian account of what constitutes the correct result of applying a rule in a new case.

${ }^{1}$ McDowell's criticisms of the communitarian interpretation have been addressed particularly to the views of Crispin Wright, as presented in Wright 1980, 2001a, $2001 b$. 
However, there is a question whether McDowell's reading simply reinstates a form of platonism which Wittgenstein's reflections show to be problematic. McDowell argues that this objection to his reading reflects an implicit commitment to the demand for a constructive account of what meaning and understanding consist in, and leads inevitably to the communitarian account he claims is untenable. On his reading, Wittgenstein does not intend to put what he calls our commonsense conception of what it is to grasp a rule in question; rather Wittgenstein reminds us of our common conception in an attempt to overcome problems and paradoxes that arise from a certain mistaken idea of what it is to go by a rule.

Thus, the dispute between McDowell and the communitarian has the following form: McDowell asserts that Wittgenstein defends the correctness of our commonsense view and the communitarian claims that he shows it to be untenable and in need of revision. Although it is true that, on McDowell's reading, Wittgenstein does not offer a constructive theory of what rule-following consists in, he is nevertheless seen as putting forward an argument to show that our commonsense conception must be correct, if we are not, unintelligibly, to deny that there is such a thing as meaning at all. Thus, the dispute between McDowell and the communitarian matches Wittgenstein's characterization of the dispute between Idealists, Solipsists and Realists:

The one party attack the normal form of expression as if they were attacking a statement; the others defend it, as if they were stating facts recognized by every reasonable human being. (PI 402)

To this extent, there is good reason to think that McDowell's reading misses Wittgenstein's philosophical aims. I want to argue that one of the problems with McDowell's reading is that it entirely neglects Wittgenstein's idea that we need to undertake what he calls a 'grammatical' investigation, that problems are solved by our coming to 'command a clear view of the use of our words' (PI 122).

\section{McDowell's Interpretation}

McDowell characterizes our commonsense conception of what it is to follow a rule as follows: 
... to learn the meaning of a word is to acquire an understanding that obliges us subsequently - if we have occasion to deploy the concept in question - to judge and speak in certain determinate ways on pain of failure to obey the dictates of the meaning we have grasped. (McDowell 1998, 221, my italics)

In the same way, he holds that our commonsense conception of objectivity commits us to "the notion of how the pattern of application that we grasp, when we come to understand [a] concept ..., extends, independently of the actual outcome of any investigation, in the relevant case' (McDowell 1998, 222, my italics). McDowell's central claim against a communitarian reading is that 'Wittgenstein's target is not the very idea that a present state of understanding embodies commitments with respect to the future [i.e. our commonsense conception], but rather a certain seductive misconception of this idea' (McDowell 1998, 223).

McDowell identifies the seductive misconception as follows: it is 'the mistaken idea that grasping a rule is always an interpretation' (McDowell 1998, 238). This mistaken idea, once it takes hold, presents us with a dilemma. On the one hand, the observation that any interpretation of a rule can itself be interpreted, and so cannot determinately fix what counts as a correct application in the future, leads to the conclusion that there is nothing that constitutes my understanding a word in a determinate way. This puts our commonsense conception of meaning and understanding under threat: it suggests that there is no such thing as grasp of a meaning which obliges us to judge and speak in certain determinate ways. On the other hand, the impossibility of accepting that there is no such thing as meaning something determinate by a word may lead us to try to put a stop to the regress by insisting that, although a sign can be interpreted, the meaning of a sign cannot be interpreted, and it is in the light of the meaning of a sign that future performances are sorted into those which are correct (i.e. in accordance with its meaning) and those which are not.

It is crucial for McDowell's reading that the second horn of this dilemma - the idea of meaning as a set of rails which determine what is correct independently of our ratification - is distinct from what he calls our commonsense conception. Part of his case for a distinction turns on his view of the structure of Wittgenstein's reflections. Thus, he argues that the problematic conception of meaning is one that only comes into view as a 
response to the apparent consequences of accepting that understanding is equivalent to an act of interpretation. He makes the point as follows:

No doubt in some contexts it is correct to say that the meaning of an expression of a rule...does not need interpretation. But here the point of saying that is to make it safe to suppose, say, that a sign-post points the way only under an interpretation. The meaning is construed as an interpretation, but one immune to what dashes the hope that a regular interpretation will bridge the gap - the realization that we have merely shifted our attention to something that, on the principles that required the shift, could itself tell us which way to go only under an interpretation. (McDowell 2009a, 106)

Thus, the seductive misconception is seen as arising independently of, and as being in effect the source of, the platonism which Wittgenstein exposes as problematic. Rejecting this form of platonism does not, as McDowell sees it, threaten the commonsense conception which is our innocuous and philosophically uncontentious starting point, even though, as he seems to concede above, the two views may sound remarkably similar. The suggestion seems to be that there are two ways of taking the words 'the meaning of an expression of a rule...does not need an interpretation', one of them problematic, the other 'correct and innocuous' (McDowell 2009b, 83). The cogency of McDowell's interpretation, as well as its satisfactoriness as a conception of rule-following, depends upon his ability to sustain this distinction between what he calls our commonsense view and the form of platomism that Wittgenstein tries to show is a mythological picture of what it is to follow a rule.

The distinction is also central to McDowell's interpretation of Wittgenstein's response to the dilemma that arises once we accept the assumption that understanding is an act of interpretation. First of all, we need to ask what makes this assumption so compelling. McDowell suggests it is because we are easily seduced into accepting that any expression of a rule - a formula, or a sign-post, say - is, in itself, a mere piece of notation, an object which is incapable of sorting performances as being in accord or failing to be in accord with it. Under these circumstances, it is natural to think that what sorts behaviour is not the sign-post or the formula, but the sign-post or the formula under an interpretation. However, once we start thinking like this, then we will be faced with the choice that the dilemma 
above presents: a regress of interpretations or a mythological conception of meaning as rails.

On the communitarian reading of Wittgenstein's response, McDowell argues, the assumptions that lead to this dilemma are not put in question. Rather, Wittgenstein is held to accept that what puts a stop to the regress of interpretations, in any particular case, is a brute disposition to apply a rule in a particular way in a new case, without any guidance from a rule. At the level of an individual's disposition to respond in new cases, no idea of acting in accord with a rule applies. The claim is that it is only when we consider the individual's brute response in relation to the brute responses of other members of the community that we can begin to assess it for correctness or incorrectness: the correct response is the one that coincides with the one that most of the members of the relevant speech community are inclined to give.

This is just the untenable view of what constitutes correctness that McDowell believes obliterates the very idea of norms. It figures in Wittgenstein's thought, he suggests, not as the conclusion of his reflections, but as a reductio of the assumptions that appear to present it as the only alternative to a problematic form platonism. On McDowell's reading, the communitarian conception of what constitutes correctness shows that the consequences of accepting the assumption which leads to the dilemma is disastrous, for it means the end of any genuine normativity, and thus the end of all meaning and understanding. Wittgenstein's response to the dilemma is, he argues, not to accept this disastrous consequence, but to reject the assumption that leads to it. What we learn from the regress of interpretations is that it is fatal to accept the idea that there is always a gap between the expression of a rule and what counts as a correct application of it, which needs to be filled by an interpretation. Thus, the conclusion Wittgenstein is held to draw is this:

We must not acquiesce in the idea that an expression of a rule, considered in itself, does not sort behaviour into performances that follow the rule and performances that do not. (McDowell 2009a, 100f.)

On McDowell's reading, this is to be seen as a call to recover our commonsense conception of meaning and understanding, by reminding ourselves of 'obvious facts' about, e.g., what we do with sign-posts. Thus, a 
great deal hangs on McDowell's ability to persuade us that what he is calling our commonsense conception, which he claims Wittgenstein retrieves by means of a series of reminders of obvious facts, is distinguishable from the form of platonism that Wittgenstein characterizes as a mythology. For, on McDowell's reading of him, Wittgenstein argues that this commonsense conception must be correct, if we are not, unintelligibly, to deny that there is any such things as meaning and understanding. He sums up the argument as follows:

If we conceive, say, sign-posts as in themselves normatively inert, so that only under an interpretation could a sign-post tell anyone which way to go, we lose our hold on the very idea that sign-posts can be understood and followed. To avoid this, we need to retrieve a bit of common-sense: that people who are party to the relevant practice are told what direction to go in by sign-posts themselves, not by sign-posts under an interpretation. If there is more work to be done, it is to loosen the grip of the conception according to which an expression of a rule, for instance a sign-post, is, in itself, normatively inert. To do that, we need to administer what Wittgenstein calls "reminders" (PI 127), not put forward philosophical hypotheses. (McDowell, 2009a, 104)

\section{Distinguishing our commonsense conception from platonism}

There are at least two ideas that McDowell calls on in the attempt to clarify the distinction between our commonsense conception and a problematic form of platonism. First of all, he distinguishes two forms of realism. The platonist mythology takes meaning to be 'wholly autonomous' (McDowell, 1998, p.255). This seems to be the idea of something like an expression of a rule which intimates to anyone who is presented with it, independently of whether they have undergone training with the relevant expression, what counts as acting in accord with its demands. This is 'the supposition that meaning takes care of itself' in an extreme form, one on which the idea of a customary practice of using signs plays no role, and the idea of initiation into such a practice is not seen as a condition of the capacity to understand or follow a rule. It is, McDowell claims, this extreme form of realism about meaning - the idea of meaning as a self-interpreting rule - that Wittgenstein's reflections undermine.

However, McDowell argues, this leaves quite untouched the idea that, given a practice of employing expressions, those expressions possess 
a meaning which, for anyone who grasps it, sorts future performances into those which accord and those which fail to accord with it. Thus, the constraints imposed by, say, a sign-post do not have the platonist autonomy of the super-realist picture. Rather, a sign-post becomes a meaningful item only if there is a customary use of sign-posts, and 'to be capable of being told what to do by a sign-post, one needs to have been initiated into an appropriate practice' (McDowell 2009a, 101). However, given that one has been thus initiated, McDowell argues, 'the subject is such that the signpost itself, not the sign-post under an interpretation, tells her which way to go' (McDowell 2009a, 101).

The first question one wants to ask is whether McDowell's way of making the distinction enables us to see why it is that the platonist mythology is undermined by Wittgenstein's reflections and McDowell's more modest form of realism escapes them. Is the switch, from the idea of a rule's exerting an absolutely autonomous constraint on its application to the idea that its ability to constrain what counts as a correct application comes into being only as a result of the existence of a practice of employing it, enough to purge the idea of a rule's determining what constitutes a correct application of it - of a 'logical fit' between a rule and its application - of its mystery? Let's take Wittgenstein's example of hearing and understanding the word 'cube'. Let's agree that what comes before my mind when I understand the word is a drawing of a cube ${ }^{2}$. McDowell's thought is that, considered in itself, independently of its employment in our practice, the drawing does not introduce any constraints on its application, but is interpretable, and thus applicable, in indefinitely many ways. However, once we have been trained in our ordinary practice of employing the picture, then the picture which comes before my mind does determine what counts as a correct application of it. Wittgenstein's rejection of the first idea, McDowell claims, is not to be confused with a rejection of the second;

${ }^{2}$ There is, of course, no suggestion in McDowell that a picture, or an explicit statement of a rule, must come before my mind when I hear and understand a word. The word 'cube' itself can, through the existence of practice into which I am initiated, become a 'meaningful item' which sorts future performances into those that accord and those that fail to accord with its meaning. However, Wittgenstein's example provides a case in which it is possible to explore in more detail what this idea amounts to. 
the claim is that Wittgenstein accepts the second and denies that the idea of the picture's imposing a constraint, understood in this sense, is an illusion.

Compare this with what Wittgenstein actually says, first at the end of PI 139:

The picture of the cube did indeed suggest a certain use to us, but it was possible for me to use it differently (aber ich konnte es auch anders verwenden).

If McDowell's reading is correct, shouldn't he have said that it is possible for the picture to be used differently, rather than that $I$ was able to use it differently, for, on McDowell's reading, the result of my training is that the picture itself acquires a normative force. And when Wittgenstein asks, in $P I$ 140, 'Is there such a thing as a picture, or something like a picture, that forces a particular application on us; so that my confusion lay in confusing one picture with another?', shouldn't the answer, on McDowell's reading be 'Yes'? For his suggestion is that there are two kinds of picture, or at any rate two ways for a subject to apprehend a picture: as a mere piece of notation, interpretable in indefinitely many ways, and as a 'meaningful item' which, in virtue of the subject's mastery of a practice of employing the picture, 'in itself' possesses the capacity to sort behaviour into what accords with it and what does not. What is needed for a picture to have the status of a meaningful item with normative implications is that it has a customary use and the subject has been trained in that use. Yet this is not what Wittgenstein says. Rather, he remarks:

...our 'belief that the picture forced a particular application upon us' consisted in the fact that only one case and no other occurred to us ....

What is essential is to see is that the same thing can come before our minds when we hear the word and the application still be different. Has it the same meaning both times? I think we shall say not. (PI 140)

There is, then, nothing in the discussion of PI 139ff to suggest that Wittgenstein is anxious to distinguish a noxious and an innocent version of the idea that a picture which comes before my mind when I hear and understand a word 'in itself' determines what counts as accord with it. It is true that in PI 141 Wittgenstein responds to the interlocutor's question, 'but ... can't an application [of the schema] come before my mind?', by saying 'It can'. However, it is crucial that he follows this up by saying 'only we need to get clearer about our application of this expression'. This is a call for the 
grammatical enquiry which, I want to argue, McDowell neglects. McDowell takes it that in responding, 'It can', Wittgenstein is accepting that there is, after all, a determinate state of understanding a picture or a sign-post, in which what counts as a correct application of it is determinately fixed. I want to argue that this is to assume the very misconception of the grammar of the expression 'the application comes before my mind' that Wittgenstein's investigation aims to diagnose.

Thus, McDowell is assuming that in saying, 'It can', Wittgenstein is reverting to some version of the idea that he has just rejected - the idea that the picture that comes before my mind when I understand the word 'in itself' determines its correct application - but there is, I want to claim, nothing to support this idea. The only idea of "constraint" in connection with the picture which comes before our minds that Wittgenstein appears to acknowledge is this: although there are different things that we should be prepared to call an application of the picture, 'only the one case and no other occurred to us'. Asked whether there can be a collision between the picture and its application, Wittgenstein responds: 'There can, inasmuch as the picture makes us expect a different use, because people in general apply this picture like this' (PI 141). Thus, he points to clash between a particular application and the regular use of the picture, rather than between an application and what the picture which comes before my mind, in virtue of my training in its use, 'in itself' requires.

McDowell's second way of approaching the distinction he needs to draw is to argue that the platonist mythology imports the idea of 'following a rule as the operation of a super-rigid yet (or perhaps we should say 'hence') ethereal machine' (McDowell 1998, 230), whereas our commonsense conception is innocent of this idea. As McDowell sees it, the platonist mythology leads to a conception of the mind as 'a queer kind of medium', 'the mysterious seat or origin of meaningfulness'; 'breathing life into otherwise dead signs is pictured as an occult feat of which only something as special as the mind could be capable' (McDowell 2009b, 85). In the same way, a platonist conceives 'successive performances in the course of, say, extending a number series [to] reflect a quasi-magical efficacy exerted by a configuration in [a] mysterious medium' (McDowell 2009b, 85). This is to picture the mind 'as the locus of configurations from which performances that manifest understanding flow, in a way that is like the way 
events flow from states of regular mechanisms or bits of apparatus except that this machinery is mysteriously capable of placing its output in the normative light constituted by the output's being correct or incorrect in the light of the configuration from which it flows' (McDowell 2009b, 85).

The question we need to ask is whether what McDowell calls our commonsense conception is not equally committed to the problematic idea "“... that what I do now (in grasping a sense) determines the future use [not] causally and as a matter of experience, but that in a queer way, the use itself is in some sense present"' (PI 195). It is, on the face of it, hard to see how else we are to understand McDowell's characterization of what our commonsense conception amounts to. For he holds that it is part of our commonsense conception that understanding is a 'definite state that we come to be in when we come to understand the principle of a series', that this is 'a state that sets in in its entirety at the relevant moment' [when we come to understand the series], and that 'in the light of [it] it is completely settled what numbers it is correct to write when one reaches a certain point in extending the series' (McDowell 2009b, 95). What is this but the idea that 'the use itself is in some sense present' in my act of understanding, so that my future performances are 'in a queer way' already anticipated in that act; their shadow is there and sets the standard for whether what I actually do is correct or incorrect?

In claiming that there is a distinction to be made here, McDowell is inclined to draw comfort from the way PI 195 continues:

But of course [the use is present], 'in some sense'! Really the only thing wrong with what you say is the expression "in a queer way". The rest is all right; and the sentence only seems queer when one imagines a different language-game for it from the one in which we actually use it.

McDowell sees this as a licence to assert that Wittgenstein does not completely reject the idea that there is a state which 'sets in in its entirety', and which 'completely settles' what behaviour counts as accord in the future. Rather, he thinks that this idea only needs to be purged of its 'queerness', and this, McDowell suggests, is done by disconnecting the idea that the use is already present in the act of understanding from the picture of the mind as an occult medium or ethereal machine. And, for McDowell, this means recognizing the role of a practice, and initiation into a practice, in giving 
whatever comes before the mind its normative force. But the question that arises is what Wittgenstein means when he says that 'the sentence only seems queer when one imagines a different language-game from the one in which we actually use it'. For McDowell this does not mean recognizing that it is not a language-game in which we attribute a determinate state which anticipates the future, but merely recognizing that someone can be in the determinate state which constitutes mastery of a rule only if he has been initiated into a practice of using it. However, it is also possible to take it that Wittgenstein's point here is that the use of the words, 'the use itself is in some sense present', is quite other than the picture of a determinate state which anticipates what counts as a correct application of the picture suggests.

That this is how we should understand Wittgenstein is supported by the conclusion he draws in PI 196:

In our failure to understand the use of a word we take it as the expression of a queer process.

This suggests that Wittgenstein sees the villain of the piece as the idea that 'the use itself is in some sense present' requires the idea of a process, something which takes place when we understand, that is, the very idea to which McDowell believes he remains committed. The point is that if we look at the use of the word, we will see that no such process is in question. This seems to be confirmed by what Wittgenstein goes on to say in PI 197:

"It is as if we could grasp the whole use of a word in a flash."-And that is just what we say we do. That is to say: we sometimes describe what we do in these words. But there is nothing astonishing, nothing queer, about what happens. It becomes queer when we are led to think that the future development must in some way already be present in the act of grasping the use and yet isn't present.-For we say that there isn't any doubt that we understand the word, and on the other hand its meaning lies in its use.

It is very hard to see how McDowell's commonsense conception gets us beyond this 'queer idea': that, insofar as the meaning of a word lies in its use, the use of the word must be in some way already present in the act of understanding. There is just no reason to believe that Wittgenstein distinguishes between a noxious and an innocent version of this idea. Rather, he wants to persuade us that the idea that the future use must be in some way 
already present in the act of understanding is based on a misconception of how the words 'understand', 'I suddenly understood', 'I already meant it at the time', 'This application does not fit with the word as I meant it', etc. are actually used: the language-game that is played with these words is quite other than we think. If this is correct, then McDowell's mistake is to suppose that in acknowledging that these things are just what we do say, Wittgenstein is thereby committing himself to a certain conception of something. All he is acknowledging is that these words are used, or one might say, correctly used on certain occasions; the question of how they are used, however, is something which awaits clarification through the grammatical investigation that Wittgenstein wants us to undertake.

If this is right, then it suggests that we should see what McDowell calls 'our commonsense conception' of what meaning and understanding consist in, or of what constitutes accord, or of what the objectivity of our judgements requires, not as something which Wittgenstein's reflections are intended to reinstate, but as things which we are 'inclined to say' about meaning and understanding, and which call for philosophical treatment. On this view, what McDowell calls our commonsense conception is just a picture which we find very natural; it has the same status as what a mathematician is inclined to say about the objectivity and reality of mathematical facts.

Wittgenstein expressed his attitude towards the conceptions or pictures we find natural at PI 254: "What we 'are tempted to say' in such a case is, of course, not philosophy; but its raw material"; it is "something for philosophical treatment'. There is clearly no sense here that what the mathematician is inclined to say is something that passes for innocent common sense, that Wittgenstein distinguishes it from what might be called philosophical platonism, or that his objective is to show that it is nothing more than statements of obvious facts. It is simply a picture, one which we find natural, but one which, as it turns out, gives rise to what Wittgenstein tries to show is a misconception of the grammar of mathematical propositions: the picture leads us to imagine a language-game for mathematical sentences which is quite other than the one that is actually played with them. In the same way, McDowell's commonsense conception of the act of understanding is a picture which we find natural, but which for all that gives rise to a misconception of the language-game which we 
actually play with the words 'understand', 'mean', 'meant', and so on. Thus:

Frege somewhere says that the straight line which connects any two points is really already there before we draw it; and it is the same when we say that the transition, say in the series +2 , have already been made before we make them orally or in writing - as it were tracing them.

One might reply to someone who said this: Here you are using a picture....

[I]f...the transitions which someone is to make on the order 'add 2' are so determined by the training that we can predict with certainty how he will go, even when he has never up to now taken this step - then it may be natural to us to use this as a picture of the situation: the steps are already taken and he is just writing them down. $(R F M, \mathrm{I}, 21-22)^{3}$

If this is right, then the picture that McDowell calls our commonsense conception is the starting point for Wittgenstein's reflections: it provides his investigation with 'its raw materials'. And this fits the order which is discernible in Wittgenstein's remarks on rule-following much better than McDowell's account of it, in which Wittgenstein is held to start from the idea that understanding is an act of interpretation. For the question that marks the opening of Wittgenstein's discussion is not, as McDowell's reading suggests it should be, 'How does a mere sign acquire its capacity to determine what counts as in accord with it?' Rather, it is the following question:

When someone says the word "cube" to me...I know what it means. But can the whole use of the word come before my mind, when I understand it in this way? ...Can what we grasp in a flash accord with a use, fit or fail to fit it? And how can what is present to us in an instant, what comes before our mind in an instant, fit a use? (PI 139)

It seems very natural to suppose that what Wittgenstein is invoking here is precisely our commonsense picture of meaning and understanding, which he then subjects to 'philosophical treatment'. What the treatment shows is that the application which we are inclined to make of this picture is empty. The regress of interpretations shows us that there is nothing that can do the

${ }^{3}$ I don't want to suggest that Wittgenstein believes that the pictures we find natural are false. The question is: what is their application. What does the idea that 'the steps are already taken' amount to? We get onto difficulty when we think the application of the picture is more straightforward than it is. 
work that this picture tries to assign to the meaning of a word. It is not, on this reading, that Wittgenstein intends to use this as the basis for suggesting that there is something problematic or incorrect about, for example, our use of the words 'But I already knew, at the time when I gave the order, that he ought to write 1002 after 1000'. The point is only that what McDowell calls our commonsense conception - the picture of meaning as dictating how an expression is to be applied - does not understand this use, but puts a false interpretation on these words, and then draws the queerest conclusions from it.

\section{McDowell's reading of $P I 201$ and $P I 198$}

This brings us to McDowell's interpretation of PI 201. McDowell points out, quite correctly, that the opening words of the second paragraph-'It can be seen that there is a misunderstanding here'-indicate that Wittgenstein does not accept the paradox with which the remark begins. However, McDowell then interprets what follows these opening words as a simple restatement of the paradox of paragraph one:

What could constitute my understanding, say, the "plus" sign in a way with which only certain answers to given addition problems would accord? Confronted with such questions, we tend to be enticed into looking for a fact that would constitute my having put an appropriate interpretation on what I was told and shown when I was instructed in arithmetic. Anything we hit on as satisfying that specification contents us only "for a moment"; then it occurs to us that whatever we have hit on would itself be capable of interpretation in such a way that acting in conformity with it would require something quite different. So we look for something that would constitute my having interpreted the first item in the right way. Anything we come up with satisfying that specification will in turn content us "only for a moment"; and so on: "any interpretation still hangs in the air along with what it interprets, and cannot give it any support" (PI 198). (McDowell 1998, 229)

The difficulty with this is that, if the opening of the second paragraph simply repeats the paradox of the first paragraph, how can it also be the 'fact' which shows us that the paradox of the first paragraph rests on 'a misunderstanding'? At the end of the first paragraph, we are left feeling that, if the rule itself does not determine what counts as accord with it, then our use of a rule is completely unconstrained: 'there would be neither accord 
nor conflict here'. Wittgenstein's response in the second paragraph is to suggest that we can see that this is a misunderstanding 'from the mere fact that in the course of our argument we give one interpretation after another; as if each one contended us at least for a moment, until we thought of yet another standing behind it.' The thought seems to be that we can see that the paradox arises out of a misunderstanding simply by observing that in the course of our discussion we have continually come up with pictures and rules that $d o$ seem to us to require or compel a particular use, i.e. which seem to us to meet our demand for a 'superlative link' between a rule and its application. It is only when someone points out to us that we would be prepared to acknowledge a different use as an application of the rule or picture that we even become aware of the possibility of using it differently. Normally, the possibility of these other applications doesn't even occur to us; we simply apply the picture or rule in the way we have been trained - in the way that accords with our practice of using it — and nothing occurs to worry us.

Clearly, McDowell does not want to read the opening sentence of the second paragraph of PI 201 this way, for that is to accept that Wittgenstein points to our natural way of responding to the rule as the way out of the paradox created by the regress of interpretations. For McDowell, Wittgenstein's way out of the paradox comes only in the second sentence of the second paragraph:

The right response to the paradox, Wittgenstein in effect tells us, is not to accept it but to correct the misunderstanding on which it depends: that is, to realize "that there is a way of grasping a rule which is not an interpretation". (McDowell 1998, 229)

And McDowell takes this as equivalent to an invocation of our commonsense conception: that, for anyone who has undergone the appropriate training, the rule itself determines what counts as accord with it, without need of an interpretation.

However, this is to ignore the second half of the sentence, in which Wittgenstein invokes, not the commonsense picture of the rule itself imposing a constraint, but our ordinary criteria for settling whether a rule has been obeyed or not. The whole sentence reads: 
What this shews is that there is a way of grasping a rule which is not an interpretation, but which is exhibited in what we call "obeying the rule" and "going against it" in actual cases. (final italics mine)

I take the 'this', in 'What this shews', to refer to the fact-pointed to in the previous sentence and held to show that the paradox rests on a misunderstanding - that, when we are first confronted by a familiar expression of a rule, we respond to it immediately, without formulating or selecting among hypotheses about how it is to be applied. As McDowell emphasises, our life with signs, such as the plus sign, or a sign-post, is such that the question of interpretation does not normally arise: we simply respond in the way we have been trained, in a way that has become second nature to us. This is the way of grasping a rule which is not an interpretation: it is an immediate response. However, what the remainder of the sentence clearly indicates is that this immediate response counts as a case of 'obeying a rule' or 'going against it' in virtue of the existence of a practice in which what we do is called 'obeying the rule' or 'going against it'. There is no sense that Wittgenstein is appealing to the normative properties of the 'rule itself', or of the mental state that a subject who grasps a rule is in, as the place to look for what makes his future performances in accord with the rule. If we want to understand what makes his response a case of obeying the rule, then we need to look at the criteria by which his performances are assessed- "what we call "obeying the rule" and "going against it" in actual cases' - and not for a mythological link, a kind of 'logical fit' - between the item that comes before his mind and what he goes on to do.

A similar objection arises in connection with McDowell's reading of PI 198:

"Then can whatever I do be brought into accord with the rule?"- Let me ask this: what has the expression of a rule — say a sign-post—got to do with my actions? What sort of connexion is there here?-Well, perhaps this one: I have been trained to react to this sign in a particular way, and now I do so react. "But that is only to give a causal connexion: to tell how it has come about that we go by the sign-post; not what this going-by-the-sign really consists in."On the contrary; I have further indicated that a person goes by a sign-post only insofar as there exists a regular use of sign-posts, a custom.

What Wittgenstein points to at the end of this remark is the practice which supplies the background to the action which he performs in responding to a 
sign-post in the way he's been trained. There is a practice of using signposts, and in the context of this practice, in certain circumstances, including his having been trained in the use of sign-posts, doing this, is a criterion of following it.

Compare this with McDowell's reading:

When I follow a sign-post, the connection between it and my action is not mediated by an interpretation of sign-posts that I acquired when I was trained in their use. I simply act as I have been trained to. This prompts an objection, which might be paraphrased on these lines: "Nothing in what you have said shows that what you have described is a case of following a rule; you have only told us how to give a causal explanation of a certain bit of (what might as well be for all that you have said) mere behaviour." The reply... is that the training in question is initiation into a custom. If it were not that, then the account of the connection between sign-post and action would indeed look like an account of nothing more than brute movement and its causal explanation; our picture would not contain the materials to entitle us to speak of following (going by) a sign-post. (McDowell 1998, 239)

Here there is the sense of an emergence of a new kind of connection between the sign-post and my action, one that 'in itself' makes my action accord or fail to accord with what the sign-post in-itself requires, and which therefore entitles us to speak of my performance as a case of going by a rule. But we still have no idea of what this new kind of connection is, and so we seem to be back with the mythological idea that 'the rule, once stamped with a particular meaning, traces the lines along which it is to be followed through the whole of space' (PI 219).

\section{Recognizing the ground that lies before us as ground}

McDowell invokes the following in support of his interpretation of Wittgenstein on rule-following:

The difficulty here is not, to dig down to the ground; no, it is to recognize the ground that lies before us as ground. (RFM VI, 31)

McDowell interprets this remark as follows:

By Wittgenstein's lights, it is a mistake to think we can dig to a level at which we no longer have application for normative notions (like "following according to the rule"). (McDowell 1998, 242) 
On McDowell's reading, digging below this level is thinking that an understanding of what following a rule amounts to must start from a base level at which all that is in view is mere dispositions to respond: something that can be characterized without normative notions like "following according to the rule". Once this step is taken, McDowell argues, we are left trying to reconstruct the notions of meaning and understanding from this nonnormative base, but what we achieve is, at best, a mere matching of regularities, with nothing genuinely normative in view. If, on the other hand "we refuse to countenance sub-"bedrock" (meaning-free) characterizations of what meaning something by one's words consists in' (McDowell 1998, 252), then we can give substance to the notion of meaning as something which can be grasped by the mind and with which future performances can be in accord, while avoiding 'the fantastic mythology of the super-rigid machine'. Then all we need to do is to note that what brings the above"bedrock" (normative) characterizations of what meaning something by one's words consists in into the picture is the existence of a custom, a practice, an institution. Thus, if there exists a practice of using sign-posts, the sign-post ceases to be normatively inert and has the capacity, in itself, to sort performances into those which accord and those which do not. From the above-"bedrock" perspective, the connection between the picture which comes before the mind and the subject's application of it, is not merely causal: the subject is such that the picture itself, not the picture under an interpretation, tells her how it is to be applied.

Thus, on McDowell's reading recognizing 'the ground that lies before us as ground' does not mean attending to our actual use of the words 'Now I understand', etc, but insisting that what is grasped in an act of understanding, say, the principle of a series is something that is not in itself normatively inert, and which therefore allows us to make sense of the idea that it imposes a normative constraint on what the subject goes on to do. It means, in other words, not abandoning the idea that, once I am initiated into the practice, 'the rule itself' intimates the way I am to go, but rather insisting that this is how we must characterize the object that comes before my mind when I either see or imagine the rule. I have already argued that it is quite unclear whether McDowell succeeds in distinguishing this idea from the idea of a 'queer' connection between the rule, or the act of understanding it, and the use I go on to make of a word. I now want to suggest 
that there is another way to understand what the idea of recognizing 'the ground that lies before us as ground' amounts to. I think that this will also begin to indicate why it is a mistake to suppose that rejecting McDowell's reading leaves us with only a communitarian reading as an alternative.

The reading of Wittgenstein I want to recommend is one that starts from the idea that the concept of a perspicuous representation is central to a proper understanding of his thought. This is closely connected with the idea that the investigation he undertakes is properly called a 'grammatical' one. It is impossible to sum up Wittgenstein's grammatical investigation of our use of the words 'Now I understand', 'He has grasped the principle of the series', 'I already meant at the time...', 'The steps are determined by the formula', and so on. However, it is important to note that his investigation of how these words are used starts from the fact that calculating, giving and obeying orders, measuring, reporting, describing, and so on are part of human natural history. All of these activities involve the idea that only certain performances count as correct: as working out the result of an addition sum, as carrying out an order, as measuring the length of the table, and so on. Our all getting the same results is, Wittgenstein suggests, essential to what we call calculating, measuring, reporting, describing, etc, but this does not mean that to give the result of, say, a calculation or a measurement is equivalent to saying, 'The majority of human beings, asked to do this, will get this as a result'. The latter statement is an anthropological statement about the majority of human beings, and it is tested, like all empirical statements, by experience. The result of a calculation, by contrast, is a mathematical proposition - $25 \times 25=625$ ' - which is justified, if the question of justification arises, by reference to the rules of calculation which function as paradigms in our practice; the result of a measurement is a statement of length - 'The table is 3 metres long' - which is justified, if the question of justification arises, by reference to procedures which function as norms in our practice; and so on. This is simply a description of what we do.

The mistake, Wittgenstein believes, is to think that anything more than the accumulation of painstaking descriptions of what we do- of differences between language-games - is needed to remove the philosophical problems that a certain natural picture of what is involved in going by a 
rule gives rise to ${ }^{4}$. He does not, I believe, attempt to justify this view of the role of a description of our use words by appeal to a philosophical view such as idealism, or to the idea that our ordinary ways of talking determine what kinds of thing exists. Rather, he tries to show that simply by carrying out the kind of grammatical investigation he recommends, the problems which arise as the result of our commitment to a particular picture of what must be the case, although we cannot see how it is the case, completely disappear. It is, however, the temptation to 'say something more', something that would justify or ground the distinctions our ordinary use of words reveals - for example, the distinction between 'Everyone asked to multiply 25 by itself gets 625 as a result' and ' $25 \times 25=625$ ' - which Wittgenstein believes we must, at all costs, resist.

My suggestion is that McDowell can be seen to succumb to this temptation insofar as he believes that there is real work to be done to show that our ordinary ways of talking - our saying, for example, 'If you multiply 25 by itself, then you will get 625 as the result', not as a prediction, but as a statement of what counts as carrying out the multiplication - are intelligible. In this way, a 'remarkable act of mind' (PI 38) is introduced which, it seems, must exist if our ordinary ways of speaking are to make sense. I've tried to show that this misrepresents Wittgenstein's philosophical aims and falls into the precisely the difficulties which the remarks on rulefollowing set out to overcome: when we try to identify this remarkable act of mind, nothing that we come up with satisfies us.

All this suggests a different way of understanding the remark from the Remarks on the Foundations of Mathematics quoted earlier:

The difficulty here is not, to dig down to the ground; no, it is to recognize the ground that lies before us as ground. (RFM VI, 31)

4 This amounts to "quietism" only if one assumes that there is a substantial philosophical question which calls for an account of what following a rule consists in. Part of Wittgenstein's philosophical purpose, I want to argue, is to persuade the reader that the question we're asking is a conceptual one, and that what it calls for is a grammatical investigation in which we come to command a clear view of our use of words, and of the differences between language-games. He doesn't provide a philosophical justification for this approach, but by undertaking the investigation he believes our question calls for, he sets out to show that the paradoxes which arise when we try to provide an account completely disappear. 
The idea is that the ground that lies before us is our ordinary use of words and the difficulty is to recognize this as the ground, that is, as what our investigation needs to focus on. The difficulty lies, not in reaching this ground, but in resisting the temptation to go further, to 'say something more': to try to justify, or explain, or make intelligible what lies before us, by giving it a ground in the nature of things, or in what must be the case. McDowell's attempt to make a real distinction between acting on an understanding and a mere disposition to respond, which justifies, or makes intelligible, our describing a particular performance as a case of following according to a rule, is, on this reading, an attempt to dig below the ground. Not digging below the ground is, by contrast, merely a matter of noting that 'this language-game is played': in these circumstances this is a criterion of grasping the principle of the series, meaning addition by '+', going by a sign-post, and so on. Thus:

Our mistake is to look for an explanation where we ought to look at what happens as a 'proto-phenomenon'. That is, where we ought to have said: this language-game is played.

The question is not one of explaining a language-game ..., but of noting a language-game. (PI 654-5) 


\section{Literature}

McDowell, John 1998: 'Wittgenstein on Following a Rule'. In: Mind, Value and Reality. Cambridge, MA: Harvard University Press.

McDowell, John 2009a: 'How not to read Philosophical Investigations: Brandom's Wittgenstein'. In: The Engaged Intellect. Cambridge, MA: Harvard University Press.

McDowell, John 2009b: 'Are Meaning, Understanding, etc Definite States?' In: The Engaged Intellect. Cambridge, MA: Harvard University Press.

Wittgenstein, Ludwig 1998: Philosophical Investigations, trans. G.E.M.Anscombe. Oxford: Blackwell. $(P I)$

Wittgenstein, Ludwig 1978: Remarks on the Foundations of Mathematics, ed. G. H. von Wright, R. Rhees, and G. E. M. Anscombe, trans. G. E. M. Anscombe. Oxford: Blackwell. (RFM)

Wright, Crispin 1980: Wittgenstein on the Foundations of Mathematics. London: Duckworth.

Wright, Crispin 2001a: 'Wittgenstein's Rule-Following Considerations and the Central Problem of Theoretical Linguistics'. In: Rails to Infinity. Cambridge, MA: Harvard University Press.

Wright, Crispin 2001b: 'Wittgenstein's Later Philosophy of Mind: Sensation, Privacy and Intention'. In: Rails to Infinity. Cambridge, MA: Harvard University Press. 